\title{
A stinging wasp in the stomach: accidental endo- scopic diagnosis of a systemic anaphylactic reaction
}

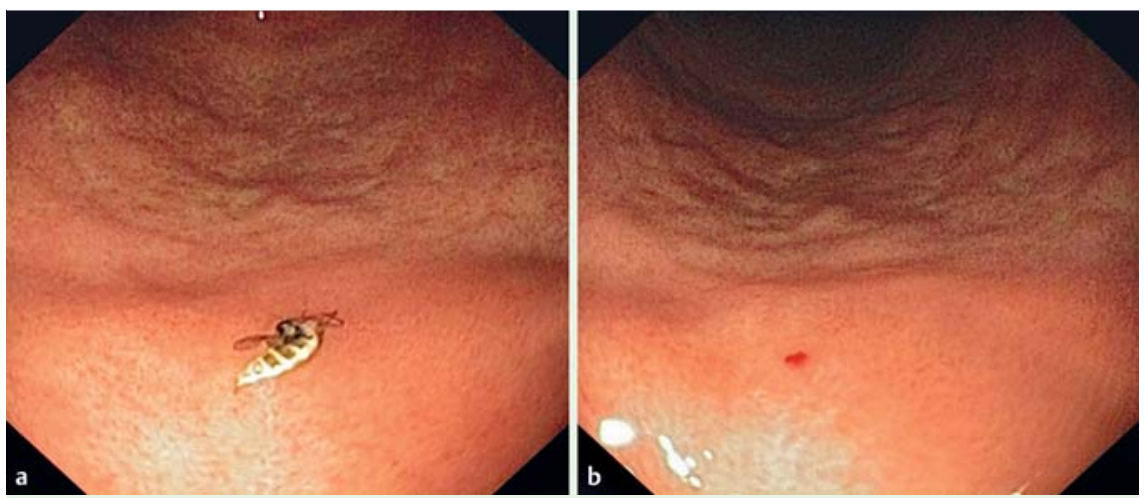

Fig. 1 Endoscopic images showing: $\mathbf{a}$ an intact dead wasp in the gastric antrum; $\mathbf{b}$ a red welt at the site of the sting.

There are only four reported cases of bees or wasps being found as foreign bodies in the esophagus or stomach [1-4]. We report the first case, to our knowledge, of a wasp puncture in the stomach causing local (acute heartburn) and systemic symptoms (anaphylaxis).

A 64-year-old woman with a history of peptic disease presented to our Emergency Department during the Sicilian harvest, in September, with acute heartburn and upper abdominal discomfort. She was also experiencing nausea, dizziness, and severe headache, and was feeling faint. On examination, the patient appeared scared and restless; she was hypotensive (systolic blood pressure $<80 \mathrm{mmHg}$ and diastolic blood pressure $<50 \mathrm{mmHg}$, measured on three occasions) but had a normal heart rate ( 68 beats/min). Abdominal physical examination, an electrocardiogram, and a chest radiograph were all normal. The results of laboratory examination revealed only neutrophilia $\left(17.8 \times 10^{9} / \mathrm{L}\right.$, being $82 \%$ neutrophils) and hypereosinophilia $\left(3.2 \times 10^{9} / \mathrm{L}\right)$.

The patient received intravenous fluid resuscitation, electrolytes, and steroids, with subsequent hemodynamic stabilization, but her abdominal symptoms persisted, with no improvement following $40 \mathrm{mg}$ of a proton pump inhibitor and prokinetic treatment. Because of her medical history, an upper gastrointestinal (GI) endoscopy was performed. We discovered, in the proximal part of the antrum on the greater curvature, an intact dead wasp with its sting visible and an underlying slightly swollen red welt in the area of the sting (๑ Fig. 1)

It appeared clear that the patient had unintentionally swallowed the wasp during the harvest and the acute abdominal pain may have been due to the sting, which then subsequently led to anaphylaxis. The patient confirmed the allergic diathesis to wasp stings and, after confirmation by skin testing and allergy-specific blood testing, specific desensitization therapy was undertaken in the medical ward. The patient was discharged after 5 days in good general condition, having been made aware of prevention strategies to minimize her exposure.

Wasp stings are common, especially during the warmer months. Approximately $10 \%$ of people who are stung by a wasp or a bee develop more widespread symptoms; $3 \%$ of people who are stung display severe allergic reactions up to anaphylaxis, which can become life-threatening if not treated promptly [5].
We performed upper GI endoscopy in this patient because we suspected peptic pathology, but unexpectedly discovered in the stomach the real cause of her heartburn and systemic symptoms. Although this case is probably unique, we stress the need for a careful medical history to be taken every time a patient presents, even in an emergency situation.

Endoscopy_UCTN_Code_CCL_1AB_2AD_3AF

Competing interests: None

\section{Girolamo Geraci, Giuseppe Modica, Carmelo Sciumè}

Section of General and Thoracic Surgery, School of Medicine, University Hospital "Paolo Giaccone" of Palermo, Palermo, Italy

\section{References}

1 Mandel G, Sod L, Greif L. Newly recognized foreign bodies in the esophagus. JAMA 1975; 231: 569

2 Farivar M. Bee sting of the esophagus. NEJM 1981; 305: 1020

3 Lynch JP, Rothstein RD. A gastric "bee-zoar". NEJM 1997; 336: 1763-1764

4 Kesseler P, Schoenemann J. Unusual summertime foreign body in the esophagus. Endoscopy $1999 ; 31:$ S24

5 Lieberman PL. Recognition and first-line treatment of anaphylaxis. Am J Med 2014; 127: $6-11$

\section{Bibliography}

Dol http://dx.doi.org/

10.1055/s-0034-1391834

Endoscopy 2015; 47: E185

(C) Georg Thieme Verlag KG

Stuttgart · New York

ISSN 0013-726X

\section{Corresponding author}

\section{Girolamo Geraci, MD, PhD}

University Hospital "Paolo Giaccone" School of Medicine

Section of General and Thoracic Surgery

Via Liborio Giuffrè n. 5

90127 - Palermo

Italy

Fax: +39-9165-52774

girolamo.geraci@unipa.it 